\title{
KOMUNIKASI VISUAL GAMBAR ANAK-ANAK PERIODE PRA-BAGAN DI SEKOLAH LABORATORIUM UNDIKSHA
}

\author{
Nuril Firdausia, Hardiman, I Gusti Made Budiarta \\ Jurusan Pendidikan Seni Rupa \\ Universitas Pendidikan Ganesha \\ Singaraja, Bali
}

e-mail: nurilfirdausia0@gmail.com, hardiman_art@yahoo.com, gustiarta97@yahoo.com

\begin{abstract}
Abstrak
Penelitian ini bertujuan untuk: (1) Untuk mendeskripsikan elemen visual yang memperlihatkan karakteristik gambar anak-anak periode pra-bagan karya siswa Sekolah Laboratorium Undiksha, (2) Untuk mendeskripsikan tema gambar anak-anak periode pra-bagan karya siswa Sekolah Laboratorium Undiksha., dan (3) Untuk mendeskripsikan makna komunikasi visual yang terdapat pada gambar anak-anak periode pra-bagan karya siswa Sekolah Laboratorium Undiksha. Metode yang digunakan adalah deskriptif kualitatif dengan teknik pengumpulan data: (1) Observasi Partisipatif, (2) Wawancara, (3) Kepustakaan, (4) Dokumentasi, (5) Life History, dan (6) Trangulasi.

Hasil penelitian: (1) Elemen visual pada Sekoah LaboratoriumUndiksha terdiri dari, (a) Elemen garis: garis vertikal, garis horizontal, dan garis melingkar, (b) Elemen warna pada periode pra-bagan ini anak memilih warna menrut selera, dan (c) Ada beberapa macam cara anak menggambar ruang, yaitu: anak menggambar berdasarkan $x$-ray, gambar penting, jauh di atas, dan dekat di bawah. (2) Tema dan sub tema gambar anak-anak dapat dikelompokkan menurut kurikulum tahun 2016-2017 yaitu (a) tema diriku dengan sub tema identitasku dan kesukaanku, (b) tema keluargaku dengan sub tema anggota keluargaku, (c) tema lingkunganku dengan sub tema rumahku, (d) tema binatang dengan sub tema binatang air dan binatang bersayap, (e) tema tanaman dengan sub tema tanaman buah dan tanaman hias, (f) tema kendaraan dengan sub tema kendaraan di air, kendaraan di darat, dan kendaraan di udara, dan (g) tema alam semesta dengan sub tema benda-benda langit dan benda-benda alam dan benda-benda langit. (3) Makna komunikasi visual pada karya anak-anak Sekolah Laboratorium dapat dideskripsikan berdasarkan subject matter (a) Pengalamanku, (b) Khayalanku, dan (c) Alamku.
\end{abstract}

Kata kunci: gambar anak-anak, komunikasi visual, periode pra-bagan.

\begin{abstract}
This research for: (1) To describe visual elements which show the characteristic of Pre chart children painting in Undiksha Laboratory, (2) To describe the theme of children painting in Undiksha Laboratory, and (3) To describe the meaning of Visual comunication from children in Undiksha Lboratory. The method i used is qualitative of descriptive with collecting some data such as: (1) Observation of Participation, (2) interview, (3)Literature, (4) Documentation, (5) Life History, and (6) Triangulation.

The result are: (1) The visual elements in Undiksha Laboratory those are, (a) there a vertical lines, horizontal lines, and Circular lines, (b) the colour of elemen in this research, the children painting a subject with clour what their like or randomly, and (c) in elemen of space there's some way few children do painting: They paint using X-ray, the most important paint, far in above and near in below. (2) The theme and the sub theme from children painting can be grouped according 2016-2017 curriculum those are: (a) theme my self and the sub theme my identity and my favorite, (b) theme my family and the sub theme my family member, (c) theme my neighborhood and the sub theme my house, (d) theme animals and the sub theme water animals and winged animals, (e) theme plant and the sub theme fruit plants and decorative plants, (f) theme vehicle and the sub theme water vehicle, ground vehicle, and air vehicle, and $(\mathrm{g})$ theme universe and the sub theme things in sky and things in nature. (3) The result from describing the meaning of visual comunication from the children in labortaory are, (a) my experience, (b) my imagination, and (c) my nature.
\end{abstract}

Keyword : children painting, pre chart period, visual comunication. 
Firdausia, dkk., Vol. 7(1), 2017, p.55-64

\section{PENDAHULUAN}

Dalam kegiatan menggambar, anak-anak sering sambil bercerita tentang apa yang sedang digambarnya. Sebagai contoh, ada seorang anak sedang menggambar sebuah mobil: Dalam proses menggambar mobil tersebut si anak mengeluarkan suara layaknya suara mobil "ngong ngooong". Setelah selesai menggambar, gambar mobil tersebut digerakkan dari dari satu anak ke anak yang lain sambil tetap anak menirukan suara mobil. Contoh lain misalnya seorang anak menggambarkan tentang pegalamannya pergi ke taman bunga bersama keluarganya. Si anak berceria tentang taman tersebut, menyebut jenis dan warna bunga, dan jenis lingkungannya atau suasana taman yang ia kunjungi.

Pendeknya, menggambar merupakan kegiatan yang sangat menyenangkan bagi anak -anak. Victor Lowenfeld / W. Lambert Brittain menjelaskan bahwa pada masa pra-bagan, anak mulai dapat mengendalikan tangannya, garis yang dihasilkan bukan lagi corengan, dan anak mulai membandingkan karya dengan objek yang dilihat.

Gambar anak yang dihasilkan pada masa ini berfungsi sebagai alat komunikasi. Sebagaimana yang digambarkan Victor Lowenfeld/ W. Lambert Brittain dala m buku Creative and Mental Growth $5^{\text {th }}$ edition:"this conscious creation of from takes on great meaning when we realize that this is the beginning of graphic communication "(1970: 117). [terjemahan bebas: penting kita sadari bahwa ini adalah awal mula komunikasi secara visual].

komunikasi visual merupakan sebuah rangkaian proses penyampaian kehendak seseorang atau pemikiran seseorang dengan maksud tertentu yang akan disampaikan kepada pihak lain dengan menggunakan media penggambaran atau visual yang terbaca oleh indera penglihatan (mata).

Gambar anak-anak pada masa pra-bagan menurut Victor Lowenfeld / W. Lambert Brittain memiliki kekhasan sebagai bentuk komunikasi visual. Masa ini berlaku secara universal. Artinya masa pra-bagan berlaku di seluruh dunia-dimana saja semua anak-anak memiliki kekhasan yang sama. Begitu pun anak-anak di Sekolah Laboratorium Undiksha yang berada pada periode prabagan dipastikan memiliki karakteristik yang sama.

Sejauh ini, penelitian dengan topik pembelajaran pada tingkat TK telah dilakukan oleh (1) Dra. Luh Suartini, M.Pd tahun 2015, dengan judul "Analisis Karakteristik Seni Rupa Anak-anak di Kecamatan Buleleng, Kabupaten Buleleng”, (2) Destiara Aulia Citra tahun 2016, dengan judul "Analisis Gambar Ekspresi Bebas Taman Kanak-kanak di Kecamatan Asembagus, Kabupaten Situbondo, Jawa Timur", dan (3) Galih Effendi tahun 2016 dengan judul "Pelaksanaan Pembelajaran Lukis Jari/Finger Painting Kelompok B di TK Negeri Pembina Singaraja".. Yang masing-masing berfokus pada karakteristik gambar anak, gambar ekspresi bebas, dan pembelajaran lukis jari/finger painting.

Sementara itu, penelitian tentang komunikasi visual gambar anak-anak, sepengetahuan penulis, belum pernah dilaksanakan, setidaknya di Singaraja. Hal tersebut menjadi alasan p enulis untuk mengadakan penelitian dengan judul "Komunikasi Visual Gambar Anak-Anak Periode Prabagan di Sekolah Laboratorium Undiksha".

Adapun rumusan masalah dari penelitian adalah (1) Elemen visual apa sajakah yang memperlihatkan karakteristik gambar anak-anak periode pra-bagan karya siswa Sekolah Laboratorium Undiksha? (2) Apa sajakah tema gambar anak-anak periode Pra-bagan karya siswa Sekolah Laboratorium Undiksha? Dan (3) Makna komunikasi visual apa sajakah yang terdapat pada gambar anak-anak periode Pra-bagan karya siswa Sekolah Laboratorium Undiksha?

Tujuan penelitian ini (1) Untuk mendeskripsikan elemen visual yang memperlihatkan karakteristik gambar anak-anak periode pra-bagan karya siswa Sekolah Laboratorium Undiksha, (2) Untuk mendeskripsikan tema gambar anak-anak periode pra-bagan karya siswa Sekolah Laboratorium Undiksha, dan (3) Untuk mendeskripsikan makna komunikasi visual yang terdapat pada gambar anak-anak periode pra-bagan karya siswa Sekolah Laboratorium Undiksha.

Manfaat penelitian dari peneltia ini adalah sebagai berikut:

(1)Untuk lembaga 
Bagi Program Studi pandidikan Seni Rupa Undiksha, penelitian ini dapat digunakan sebagai tambahan informasi mengenai makna komunikasi visual yang terdapat pada gambar anak-anak periode pra-bagan yang bisa digunakan sebagai pengajaran materi perkuliahan.

(2) Untuk guru

Penelitian ini diharapkan berguna bagi guru TK dan SD sebagai tambahan pengetahuan mengenai gambar anak-anak periode pra-bagan yang dapat dimanfaatkan dalam proses pembelajaran.

(3) Untuk penulis

Penelitian ini bermanfaat bagi penulis yang merupakan calon guru atau pendidik dalam hal perluasan pengetahuan mengenai gambar anak-anak periode pra-bagan.

\section{METODE PENELITIAN}

Penelitian ini mengunakan metode penelitian deskrptif kualitatif. Teknik pengu mpulan data menggunakan teknik observasi partisipatif, wawacara, kepustakaan, dokumentasi, life history, da triangulasi.

Penelitian ini menggunakan teknik analisis model Miles dan Huberman seperti yang dijelaskan Sudikan (2001) dengan langkah-langkah, Reduksi Data (Data Reduction), Penyajian Data (Data Display), dan Conclusion drawing/verification.

\section{HASIL DAN PEMBAHASAN}

\section{Elemen Visual Gambar Anak-anak Periode Pra-bagan.}

Elemen visual yang terdapat pada gambar anak-anak Sekolah Laboratorium Undiksha seperti yang dijelaskan Muharam (1992) terdiri dari elemen garis, elemen warna, dan elemen ruang.

\section{(1) Elemen Garis}

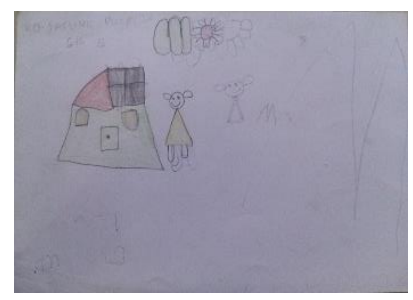

Gambar 1 karya KD. Jasline Puspita, 6 tahun,

TK Laboratorium Undiksha.

(Foto: Nuril Firdausia)

Karya KD. Jasline Puspita, memperlihatkan garis-garis yang terkendali sudah membentuk objek yang mulai dikenali. Pada gambar Jasline ini terdapat gambar rumah yang tersusun dari garis vertikal dan horizontal sebagai dinding dan atap. Sedangkan atap depan di gambar dengan dua daris miring dan horizontal yang membentuk segi tiga. Selain gambar rumah terdapat juga gambar manusia terdiri dari lingkaran sebagai kepala yang dilengkapi dengan mata, mulut, hidung, dan telinga yang berbentuk oval. Badan digambar dengan garis berbentuk segi tiga dan kaki digambarkan dengan garis lengkung.

(2) Elemen Warna

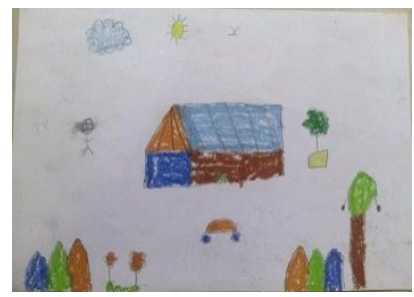


Gambar 2 Karya Putu Raditya, 5 tahun, TK Laboratorium Undiksha.

(Foto: Nuril Firdausia)

Karya Putu Raditya terlihat pada gambar ini benyak warna, yaitu: atap depan rumah berwarna orange, pada atap belakang berwarna biru, sedangkan pada dinding depan dan samping warna biru tua dan coklat, pintu di warna hijau. Pagar di depan rumah berwarna orange, hijau, dan biru, sedangkan bunga berwarna orange dan hijau. Terdapat juga gambar mobil yang berwarna orange pada badan mobil dan pada dua rodanya berwarna biru tua.

(3) Elemen Ruang

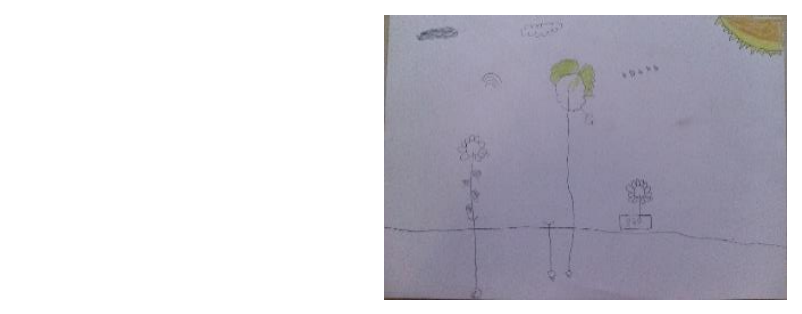

Gambar 3 Karya Kadek Pram Budi, 6 tahun, TK Laboratorium Undiksha.

(Foto: Nuril Firdausia)

Pada karya ini anak menggambarkan bunga yang timbuh dari sebuah biji yang berada dalam tanah. Dalam istilah Oho Garha (1989) disebut sebagai tembus pandang atau ( $x$-ray). Tanah tampak transparan, sehingga kita dapat melihat bahwa bunga tersebut berasal dari sebuah biji ynag di tanam di tanah. Biji itu sendiri digambarkan berakar. Terdapat juga bunga yang ada di sebuah pot, sama dengan gambar bunga yang lain, gambar bunga, biji, dan pot bunga terlihat transparan.

\section{Tema Gambar Anak-anak Periode pra-bagan}

Mengacu pada kurikulum 2013 tema yang ditemukan pada karya anak-anak Sekolah Laboratorium Undiksha adalah sebagai berikut: (1) tema diriku, (2) tema keluargaku, (3) tema lingkunganku, (4) tema binatang, (5) tema tanaman, (6) tema kendaraan, dan (7) tema alam semesta.

(1) Tema Diriku

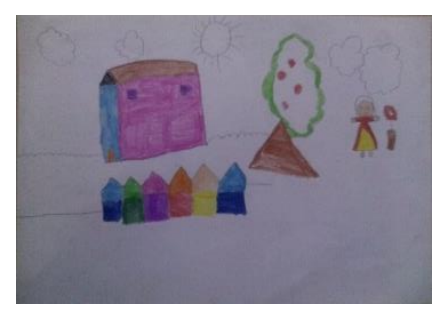

Gambar 4 Karya Anya Permata,

5 tahun, TK Laboratorium Undiksha.

(Foto: Nuril Firdausia)

Pada bidang gambar terdapat gambar rumah, pohon, pagar, awan, matahari, bunga, dan manusia. Anya menggambar dirinya sendiri yang sedang berada di halaman rumahnya. "Rumah digambar tinggi karena rumahnya bertingkat", kata si Anya. Anya juga suka bunga, maka dari itu dirinya digambar berdekatan dengan objek bunga. Di rumahnya juga terdapat pohon apel seperti apa yang ia gambarkan pada karyanya. Apa yang ada di sekitar rumah Anya, digambar sesuai 
dengan yang diingatnya. Gambarkarya Anya ini dengan demikian dapat digolongkan pada tema diriku dengan sub tema identitasku hal ini ditegaskan melalui penggambaran rumah dan lingkungannya.

(2) Tema keluargaku

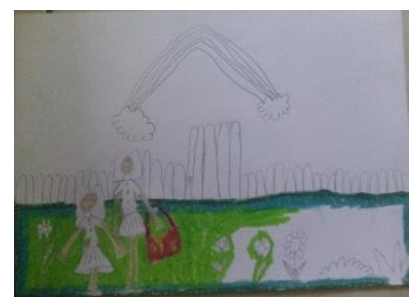

Gambar 5 Karya Hians, 7 tahun,

SD Laboratorium Undiksha.

(Foto: Nuril Firdausia)

Pada karya ini terdapat objek manusia, bunga, awan, rumput, dan pagar. Hians, 7 tahun, pembuat gambar ini menceritakan bahwa ia pernah berlibur ke taman bunga bersama ibunya, secara visual dapat dibaca bahwa dalam gambar tersebut terdapat satu suasana yang ceria di mana si anak dengan ibunya sedang berada di taman bunga. Si anak bergandengan tangan dengan ibunya, dapat diartikan bahwa anak tidak ingin jauh dari ibunya. Karya Hians ini dapat digolongkan pada tema keluargaku dengan sub tema anggota keluargaku yang ditegaska n melalui penggambaran objek aku dan ibu pada bidang gambar.

(3) Tema Lingkungaku

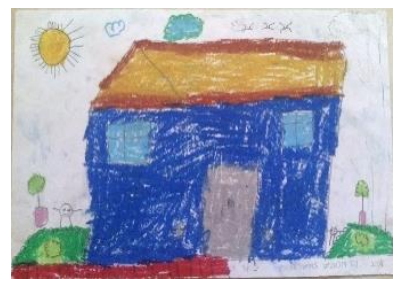

Gambar 6 Karya Ketut Rendra Suastika, 5 tahun,

TK Laboratorium Undiksha.

(Foto: Nuril Firdausia)

Terdapat berbagai objek, yaitu objek rumah, awan, matahari, bunga, rumput, burung, pagar, dan orang-orangan salju. Anak menggambarkan rumah sebagai objek utama, karena rumah digambar lebih besar dari objek lainnya. Bagian-bagian rumah juga digambar oleh Rendra, seperti jendela dan pintu. Sedangkan pada halaman rumah, anak menggambarkan pagar, bunga, dan rumput. Karya Rendra dapat digolongkan pada tema lingkunganku dengan sub tema rumahku.

(4) Tema Binatang

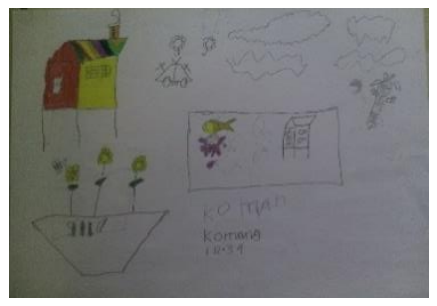


Gambar 7 Karya Komang,

7 tahun, SD Laboratorium Undiksha.

(Foto: Nuril Firdausia)

Pada karya ini terdapat objek awan, bunga, tank, rumah panggung, aquarium, ikan, kepiting, kupu-kupu. Objek-objek yang digambar oleh Komang memperlihatkan dua cara pandang yaitu rumah pangung digambar tampak depan, aquarium digambar tampak atas, tank digambar tampak samping. Karya komang ini dapat digolongkan pada tema binatang dengan sub tema binatang air dan binatang bersayap.

(5) Tema Tanaman

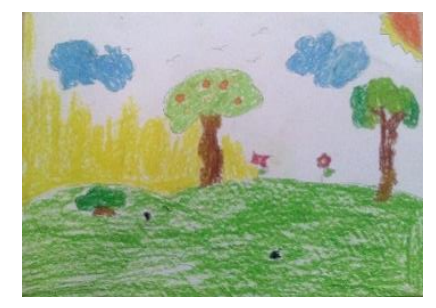

Gambar 8 Karya Ni Kadek Arumi Jovina, 6 tahun, TK Laboratorium Undiksha (Foto: Nuril Firdausia)

Karya Jovina Terdapat gambar awan, matahari, pohon, bunga, rumput, burung, dan batu. Arumi menggambar sebuah taman dengan berbagai tumbuhan diantaranya pohon apel yang sudah berbuah. Karya Jovina dapat digolongkan pada tema tanaman dengan sub tema tanaman buah dan tanaman hias seperti objek bunga dan pohon apel yang ada pada bidang gambar Arumi dan Bunga.

(6) Tema Kendaraan

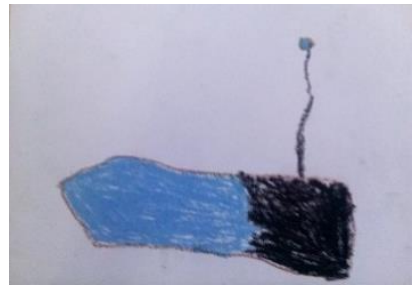

Gambar 9 Karya Ni Putu Indrina A. K, 5 tahun, TK Laboratorium Undiksha.

(Foto: Nuril Firdausia)

Pada bidang gambar terdapat objek menyerupai persegi panjang dan garis vertikal serta lingkaran kecil diatasnya. Anak tersebut menceritakan bahwa objek tersebut adalah kapal selam. $\mathrm{Si}$ anak melihat bentuk kapal selam di televisi dalam film kartun. Karya Indrina ini dapat digolongkan pada tema kendaraan dan sub tema kendaraan di air.

(7) Tema Alam Semesta

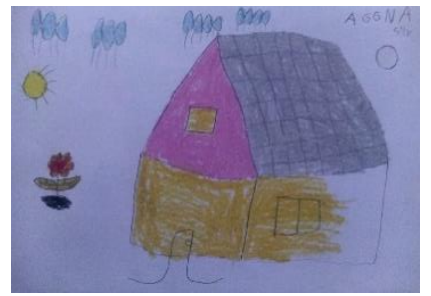




\section{Gambar 10 Karya Agna, 5 tahun, TK Laboratorium Undiksha. \\ (Foto: Nuril Firdausia)}

Pada karya ini terdapat objek rumah, awan, bunga, matahari dan bulan. Objek matahari dan bulan di gambar di atas bidang gambar yang sama, karena menurut si anak matahari sebagai pagi yang muncul dari sebelah kiri bidang gambar, sedangkan bulan sebagai malam yang ada di bagian kanan bidang gambar. Karya ini dapat digolongkan pada tema alam semesta dengan sub tema benda-benda langit.

\section{Makna Gambar Anak-anak Periode Pra-bagan}

Pembahasan tentang makna gambar diklasifikasikan berdasarkan tema cerita (subject matter) seperti yang dituturkan anak. Subject matter gambar anak-anak periode periode pra-bagan sebagai berikut: (1) pengalamanku, (2) khayalanku, dan (3) alamku.

(1) Pengalamanku

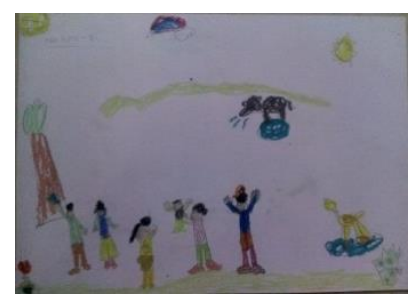

Gambar 11 Karya Putu Anggun Ascarya, 6 tahun, TK Laboratorium Undiksha.

(Foto: Nuril Firdausia)

Gambar ini menurut Anggun sendiri adalah pengalaman dia tamasya ke kebun binatang bersama keluarganya yang terdiri dari kakek, nenek, ayah, ibu, dan adiknya. Gambar ini dengan jelas memperlihatkan bagaimana suasana berlibur yang menyenangkan di kebun binatang. Tokoh aku (Anggun) terlihat melambaikan kedua tangannya begitu juga adiknya yang digendong ibunya, bahkan ayahnya juga memperlihatkan pose yang sama. Pose melambaikan tangan ini menurut penulis bisa ditafsirkan sebagai gambaran kegembiraan. Dua matahari yang digambar di sebelah kiri bidang gambar dan di sebelah kanan bidang gambar bisa dimaknai sebagai gambaran waktu atau yang sering disebut sebagai dimensi ketiga yang artinya menunjukkan waktu yang berbeda. Gambar matahari di kiri bisa dibaca sebagai pagi dan matahari di kanan bisa dibaca sebagai siang. Hal ini sebagaimana yang diakui Anggun sendiri bahwa ia bersama keluarganya berada di kebun binatang dari pagi sampai siang hari.

(2) Khayalanku

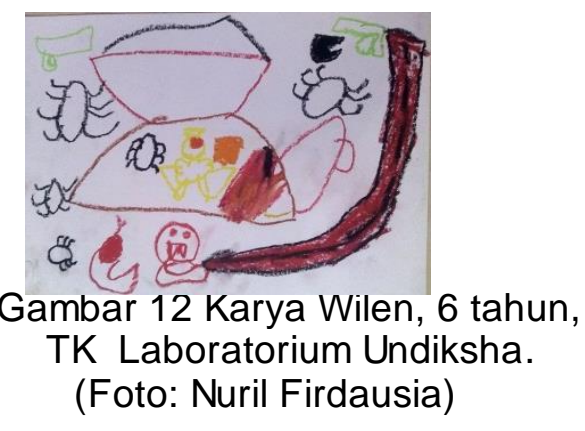

Pada karya ini terdapat objek-objek yang belum jelas bentuknya. Menurut Wilen, objek ini adalah bentuk hantu, gambar hantu terbang dari pojok kanan atas ke bawah bidang gambar 
menurut cerita Wilen. Sedangkan bentuk-bentuk lain juga meupakan bentuk hantu kata Wilen. Objek hantu yang Wilen buat berwarna-warni, ada yang berwarna merah, hitam, kuning, dan hijau. Penulis bertanya kepada Wilen, kenapa menggambar hantu? Apa Wilen pernah melihat hantu? Wilen menjawab belum pernah melihat hantu, hanya lihat di televisi melalui kartun Scooby-Doo.

(3) Alamku

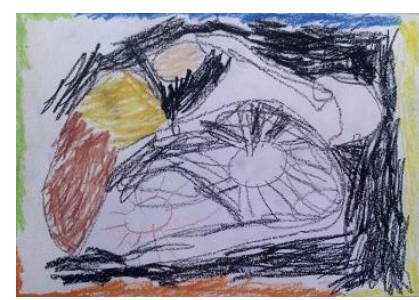

Gambar 13 Karya Kadek Bianca Angela. G, 5 tahun, TK Laboratorium Undiksha.

(Foto: Nuril Firdausia)

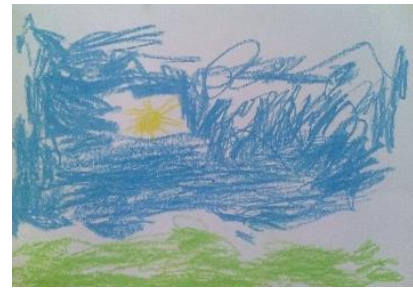

Gambar 14 Karya A. A. Ramakanta. P, 5 tahun, TK Laboratorium Undiksha.

(Foto: Nuril Firdausia)

Pada karya ini hanya terdapat objek matahari. Karya Bianca tedapat dua objek matahari yang satu berwarna hitam dan yang lainnya berwarna coklat. Penulis dapat memaknai matahari hitam sebagai malam dan matahari coklat sebagai siang. Sedangkan pada karya Ramakanta terdapat satu objek matahari berwarna kuning. Penulis menafsirkan matahari berwarna kuning menandakan siang hari.

\section{KESIMPULAN DAN SARAN}

\section{Kesimpulan}

Berdasarkan penelitian yang dilakukan di Seklah Laboratorium Undiksha, dapat ditarik kesimpulan:

Pada karya seni rupa anak-anak Sekolah Laboratorium Undiksha periode pra-bagan terdapat elemen visual garis, elemen warna, dan elemen ruang. Elemen garis tersebut berupa garis vertikal, garis horizontal, dan garis melingkar. Beberapa karya tersebut ada yang sudah berbentuk menyerupai bentuk tertentu akan tetapi belum begitu jelas, ada juga yang belum berbentuk, hanya terdapat garis-garis yang belum terkendali seperti benang kusut. Sedangkan elemen warna, anak pada periode pra-bagan ini mewarnai tidak meniru realitas alam. Elemen ruang, yang ditemukan yaitu: anak menggambar berdasarkan $x$-ray, gambar penting, jauh di atas, dan dekat di bawah

Tema yang terdapat pada karya anak-anak Sekolah Laboratorium Undiksha yaitu: tema diriku dengan sub tema identitasku dan kesukaanku, tema keluargaku dengan sub tema anggota keluargaku, tema lingkunganku dengan sub tema rumahku, tema binatang dengan sub tema binatang air dan binatang bersayap, tema tanaman dengan sub tema tanaman buah dan tanaman hias, tema kendaraan dengan sub tema kendaraan di air, sub tema kendaraan darat, dan sub 
tema kendaraan di udara, tema alam semesta dengan sub tema benda-benda langit, dan sub tema benda-benda.

Makna gambar karya anak-anak Sekolah Laboratorium Undiksha yang telah diklasifikasikan berdasarkan subject matter atau tema cerita seperti yang dituturkan anak yaitu terdiri dari: pengalamanku, khayalanku, dan alamku.

\section{Saran}

Melalui penelitian ini penulis mengajukan beberapa saran, baik pada beberapa pihak seperti mahasiswa dan masyarakat sebagai pertimbangan dalam melakukan penelitian selanjutnya.

\section{Bagi Guru}

Diharapkan hasil penelitian ini bisa memperkaya referensi dalam mengolah materi pelajaran dan memperkaya bahan pengajaran terhadap siswa tahun ajaran selanjutnya, khususnya tenang penafsiran dan pembahasan terhadap karya anak-anak. Guru juga diharapkan lebih banyak berkomunkasi dengan anak, mengembangkan metode pembelajaran yang dilakukan di sekolah. Sehingga karya yang dihasilkan oleh anak bagus dalam hal komunikasi maupun visualnya.

\section{Bagi Orang Tua}

Bagi Orang tua, diharapkan memahami ciri-ciri gambar anak, seperti elemen visual, tema dan makna gambar anak. Agar orang tua mampu memahami dan menghargai karya anak-anak.

\section{Peneliti lain}

Bagi peneliti lain diharapkan penelitian ini dapat menjadi inspirasi dan referensi agar kedepannya banyak lagi peneitian terkait dengan komunikasi visual gambar anak periode pra-bagan atau periode-periode selanjutnya.

\section{Seni Rupa Undiksha}

Saran ini ditujukan kepada Jurusan Seni Rupa Undiksha, seandainya ada mahasisiwa yang tertarik dan berkeinginan mengadakan penelitian mengenai komunikasi visual gambar anak disarankan agar dapat meneliti karya anak berdasarkan cerita yang dituturkan pada saat menggambar.

\section{DAFTAR PUSTAKA}

Citra, Desiara Aulia. 2016. Analisis Gambar Ekspresi Bebas Taman Kanak-kanak di Kecamatan Asembagus, Kabupaten Situbondo, Jawa Timur (skripsi, tidak diterbitkan) Singaraja: Jurusan Pendidikan Seni Rupa. Undiksha.

Efendi, Galih. 2016. Pelaksanaan Pembelajaran Lukis Jari/Finger Painting kelompok B di TK Negeri Pembina Singaraja (skripsi, tidak diterbitkan) Singaraja: Jurusan Pendidikan Seni Rupa. Undiksha.

Garha, Oho. 1989. Pendidikan Seni (Seni Rupa). Bandung: Angkasa.

Kurikulum 2013 Sekolah Dasar Negeri 4 Banyuasri Tahun Pelajaran 2016-2017. 2017. Jakarta: Permendikbud RI.

Lovenfeld, Victor/W. Lambert Brittain. 1970. Creative and Mental Growt $5^{\text {th }}$ Edition. United States of America: The Macmillan Company.

Muharam E. dan Warti Sundaryati. 1992. Pendidikani Kesenian I/ Seni Rupa. Jakarta: Departemen Pendidikan dan kebudayaan.

Sudikan, Setya Yuwana. 2001. Metode Penelitian Kebudayaan. Surabaya: Unesa Unipress.

Suartini, Luh. Dkk. 2015. Analisis Karakteristik Anak-anak PAUD di Kecamatan Buleleng, kabupaten Buleleng makalah disajikan dalam Seminar Pengabdian Masyarakat (laporan penelitian, tidak diterbitkan) Singaraja: Jurusan Pendidikan Seni Rupa. Undiksha. 
Firdausia, dkk., Vol. 7(1), 2017, p.55-64 